Volume 8. No. 1.1, 2020

International Journal of Emerging Trends in Engineering Research

Available Online at http://www.warse.org/IJETER/static/pdf/file/ijeter1381.12020.pdf

https://doi.org/10.30534/ijeter/2020/1381.12020

\title{
Soil Moisture Monitoring for Plant Irrigation: A Botanic Tourism Sustainability During Covid-19 Pandemic
}

\author{
K. A. F. A. Samah', M. A. M. Arip ${ }^{2}$, N. A. Deraman ${ }^{3}$, A. G. Buja ${ }^{4}$, M. N. H. H. Jono \\ ${ }^{1}$ Faculty of Computer and Mathematical Sciences, Universiti Teknologi MARA Cawangan Melaka Kampus \\ Jasin, Melaka, Malaysia, khyrina783@uitm.edu.my \\ ${ }^{2}$ Faculty of Computer and Mathematical Sciences, Universiti Teknologi MARA Cawangan Melaka Kampus \\ Jasin, Melaka, Malaysia, m.affiq1996@yahoo.com \\ ${ }^{3}$ Faculty of Computer and Mathematical Sciences, Universiti Teknologi MARA Cawangan Melaka Kampus \\ Jasin, Melaka, Malaysia, noora465@uitm.edu.my \\ ${ }^{4}$ Faculty of Computer and Mathematical Sciences, Universiti Teknologi MARA Cawangan Melaka Kampus \\ Jasin, Melaka, Malaysia, geogiana@uitm.edu.my, \\ ${ }^{5}$ Faculty of Computer and Mathematical Sciences, Universiti Teknologi MARA Cawangan Melaka Kampus \\ Jasin, Melaka, Malaysia, hasrol@uitm.edu.my
}

\begin{abstract}
This paper describes a preliminary study on the adaptation of data visualization and the Internet of Things (IoT) to monitor the soil moisture of plant irrigation to sustain botanic tourism. It is compulsory to perform a daily irrigation schedule until the plants can live independently. However, due to the Covid-19 pandemic, insufficient infrastructure, work rotation at the share-farm, and unpredictable weather, it caused inconvenience for the workers to fulfill the irrigation routines twice a day. Hence, this research aimed to design and develop a mobile-based application with monitoring features that could help workers to monitor and visualize the soil moisture at the botanical area. It is using data visualization technique and enables them to perform irrigation remotely through the application via the IoT connection that linked to a water pump. It is proven that all the features of the system were functioning well and managed to receive good system usability of $77.4 \%$.
\end{abstract}

Key words: Soil moisture monitoring, Plant irrigation, Botanic tourism, Data visualization, Internet of things

\section{INTRODUCTION}

Tourism is one of the main factors in the increased urbanization and degradation of natural resources in numerous tourist destinations along the coast. Malacca is among the top destinations chosen by Malaysians during school holidays since Malacca is known as a historical city in Malaysia. Agriculture has become one of the tourism activities in the state, thus preserving forest and nature's sustainability is deemed important. Melaka Botanical Garden is one of the famous attractions, a huge recreational space and conservation centre that spreads over 359 hectares located in Ayer Keroh, a town in the state of Malacca. There are many facilities at this park-like Malacca Forestry Museum, Prehistoric Garden, the Storyland, children's playgrounds, a suspension bridge, and watch towers. This garden has been in operation since April 1984 and was previously known as Ayer Keroh Recreational Forest. Since this park has set in the natural rainforest region, many people come for a walk here. There are walking tracks and trails that cater to people of all age groups.

Melaka Botanical Garden has been gazetted as a learning forest to provide opportunities for school and university students researching specific trees. It attracts foreign tourists on the unique Malaysian agricultural landscape and aligned with the practice done by students from the Faculty of Plantation and Agrotechnology (FPA) in Universiti Teknologi MARA (UiTM) Cawangan Melaka Kampus Jasin. The students need to get maximum benefits from their studies and play a vital role in producing well-trained professionals to the plantation and agriculture-related industries at national and international levels. FPA's academic programs do not only require students to get involved with practical and outdoor activities such as planting, irrigating, fertilizing, and harvesting, but the students also need to have solid knowledge on the sensitivity of the plants they are culturing.

In agriculture, the plant needs four basic elements to live and grow, which are air, water, soil, and sunlight [1]. Thus, an insufficient amount of light, carbon dioxide, and water can cause slow growth and one of the ways to improve the plant growth is maximizing photosynthesis as it could get enough food to grow [2]. Besides, water and soil play a vital role in providing sufficient plant water, vitamin and nutrient it needs for healthier growth. Therefore, soil moisture needs to be visualized efficiently and monitored to know how much water required for irrigation.

However, the Covid-19 pandemic outbreak has brought a significant impact on the tourism industry due to travel 
restrictions across the country and internationally. On 16th March 2020, the Ministry of Tourism, Arts and Culture announces that several tourist attractions around Malaysia are remained closed for a period of time. Tourist arrival on most of the Asia Pacific region was on a declining trend highest by Indonesia with more than $13 \%$ as the most affected country, and Malaysia was impacted by $6 \%$ [3]. This scenario causes the disturbance on the irrigation activities due to limited human sources on a shift rotation, insufficient infrastructure and unpredictable weather to maintain the growth of the plants. Subsequently, to minimize the environmental damage in any development such as tourism, it must be carried out following the principles of sustainable development [4]. In this fast technology growing age, new inventions on autonomous technologies for agriculture could potentially become the innovation key for farmers to manage their farm efficiently in bringing down the production cost and hence improve crops' yield and quality [5].

Thus, with the aim to overcome the problem, data visualization (DV) was adapted as the graphical presentation that consists of a set of data and information that uses principles of psychology to determine the usability of a wide range of raw data, before statistically transforming them into an appealing and well-structured format to highlight the important user data to make the decision [6]. Accurate moisture reading obtained and visualized in graphical graphs with the aid of the soil moisture sensor. Furthermore, this technique can help workers, researchers and students to learn the exact moisture of the soil and keep them aware of the water amount needed for proper irrigation. Proper irrigation practices help to optimum utilization of soil and water resources, thus leads to continuous agriculture [7]. Therefore, this paper presented the plant irrigation system using DV on the soil monitoring, which enables the user to perform irrigation remotely through the application via IoT that connected to a water pump.

\section{RELATED WORKS}

In this section, we describe the plant irrigation methods, data visualization and internet of things on the related issue.

\subsection{Plant Irrigation Methods}

In agriculture, there is a need to deliver water or an applicable nutritious liquid to the root of a plant in a measured manner, continuously with right amounts in growing and maintaining small plants and agricultural plantings [8]. Malaysia's position is nearby the equator line area provides the rainfall throughout the year, hot and wet climate. This tropical and unpredictable weather makes most of the plants at the early stage to be monitored by humans frequently. Three irrigation methods used; manual irrigation, drip irrigation, sprinkler irrigation and furrow irrigation.
Manual irrigation is the most common and often the most practical irrigation strategy for small native plant nurseries or farms producing a variety of species [9]. This method involves the use of standard gardening tools such as watering cans, buckets, and also hoses for daily irrigation process [10]. Drip irrigation method does not require pressurized water. Water supply is connected to a network that equipped with spaced outlets which will release the water slowly at no pressure. This system is designed to supply water to a small soil volume in which the plant's active root uptake can take place [11]. With this system, water is supplied more frequently and often daily basis to maintain the desired soil moisture condition to prevent the plant suffered from moisture stress [12]. Good design and properly installed drip irrigation system can save as much as $80 \%$ of the water normally used in other types of irrigation systems [13].

A sprinkler water system simulates rainfall by "throwing" water through the air. In contrast, the other three irrigation methods mentioned above directly apply water on or below the surface of the soil [14] in obtaining a uniform distribution with overlapping of several sprinklers [15]. Moreover, a sprinkler irrigation system will reduce evaporation loss during irrigation which is also a function of sprinkler characteristics, operating pressure, and climate factors [16]. Lastly, furrow irrigation often referred to as flood irrigation, which mainly used to germinate the seeds. This method basically will flood a field for a pre-set time to let the water infiltrated. Many fields using this technique will have the ridges and furrows features to allow the water applied through the furrows and infiltrates down into the ridges.

\subsection{Data Visualization}

Data Visualization (DV) is a data presentation method that uses the graphical or pictorial form to present data to make the audience understand the explained facts before determining the courses of action [17]. With DV, a big amount of data can be visualized in an easier way to be understood, and people no longer need to go through the data one by one. In many fields, DV can be implemented to display many types of data. For instance, in the agricultural sector, statistical data such as yield production, soil moisture, market price, and also the temperature of the surrounding of the plantation area. These data can help users to make a decision later or take a suitable action based on the presentation data. Recently, DV has slowly gained more acceptance in many sectors, especially for data science applications. Consequently, many new researchers have embarked within this study to come out with more visualization research and techniques. Speaking of technique, DV currently divided into a few techniques which are, planar visualization, temporal visualization, network visualization and also multidimensional visualization. The detailed comparison explained in Table 1. 
K. A. F. A. Samah et al., International Journal of Emerging Trends in Engineering Research, 8(1.1), 2020, 82 - 89

Table 1: SPA Comparison Description

\begin{tabular}{|c|c|c|c|c|}
\hline Attributes & Planar Visualization & $\begin{array}{c}\text { Temporal } \\
\text { Visualization } \\
\end{array}$ & $\begin{array}{c}\text { Network } \\
\text { Visualization } \\
\end{array}$ & $\begin{array}{c}\text { Multidimensional } \\
\text { Visualization } \\
\end{array}$ \\
\hline Technique & $\begin{array}{l}\text { Shows data on the } \\
\text { map or grid based } \\
\text { on the attributes or } \\
\text { values of the data } \\
\text { such as coordinates }\end{array}$ & $\begin{array}{l}\text { Illustrates temporal } \\
\text { data for a certain } \\
\text { period in a time flow }\end{array}$ & $\begin{array}{l}\text { Shows the } \\
\text { relationship or } \\
\text { hierarchical data } \\
\text { relation of each } \\
\text { different data } \\
\text { category }\end{array}$ & \begin{tabular}{|l} 
Represents \\
multidimensional \\
data in lower \\
dimensional form \\
such as 1 or \\
2-dimensional form \\
of data
\end{tabular} \\
\hline Type of Data & $\begin{array}{l}\text { - Spatial data } \\
\text { - Geographical data }\end{array}$ & - Temporal data & - Hierarchical data & $\begin{array}{l}\text { - Multidimensional } \\
\text { data } \\
\text { - Data with more than } \\
1 \text { features }\end{array}$ \\
\hline Sector Field & $\begin{array}{l}\text { - Crime and Justice } \\
\text { - Geographical } \\
\text { Science }\end{array}$ & $\begin{array}{l}\text { - Economic } \\
\text { - Social Science }\end{array}$ & $\begin{array}{l}\text { - Social Network } \\
\text { - Biology }\end{array}$ & $\begin{array}{l}\text { - Risk Management } \\
\text { - Information Science } \\
\text { - Banking }\end{array}$ \\
\hline Type of Visualization & $\begin{array}{l}\text { - } \text { Choropleth } \\
\text { - Dot Distribution } \\
\text { Map } \\
\text { - Cartogram }\end{array}$ & $\begin{array}{l}\text { - } \text { Timeline } \\
\text { - Time Series } \\
\text { - Gantt Chart }\end{array}$ & $\begin{array}{l}\text { - Node-link Diagram } \\
\text { - Alluvial Diagram }\end{array}$ & $\begin{array}{ll}\text { - } & \text { Pie Chart } \\
\text { - } & \text { Histogram } \\
\text { - } & \text { Scatter Plot }\end{array}$ \\
\hline
\end{tabular}

In conclusion, temporal visualization is chosen because it is suitable to illustrate data that have a relation with time as this study visualized the data using a few time intervals such as by a minute, an hour, 12 hours, a day, and also a week. Furthermore, the nature of data used is temporal data that consisted the moisture reading and when the data is collected. Thus, temporal visualization technique can help users to easily understand the information such as soil moisture as it can construct a time series graph that provides a better understanding.

\subsection{Internet of Things}

The Internet of Things (IoT) refers to the use of intelligently connected devices and systems to leverage data gathered by embedded sensors and actuators in machines and other physical objects. With the popularity of the IoT, it is expected that it will spread rapidly and dominating the IT world over the coming years by unlocking a feature called 'Connected Life'. A new dimension of services that delivers a higher quality of life of consumers and productivity of enterprises will be created by this convergence [18]. This rapidly growing technology will one day ease our daily routines, making everything easier and faster.

In 2003, more than 500 million devices used to connect to the internet by 6.3 billion people globally [19]. This figure illustrated a big percentage of the human population is using the internet since 2003. Furthermore, IoT has a proven ability to enhance decision making by underpinning specific solutions, improving productivity, and improving energy efficiency, security, health and education that will make our daily life better [19]. The IoT consists of 4 components which are sensors, network, analytics, and also user interface. These components are used in the 4 layers of IoT architecture, as illustrated in Figure 1.

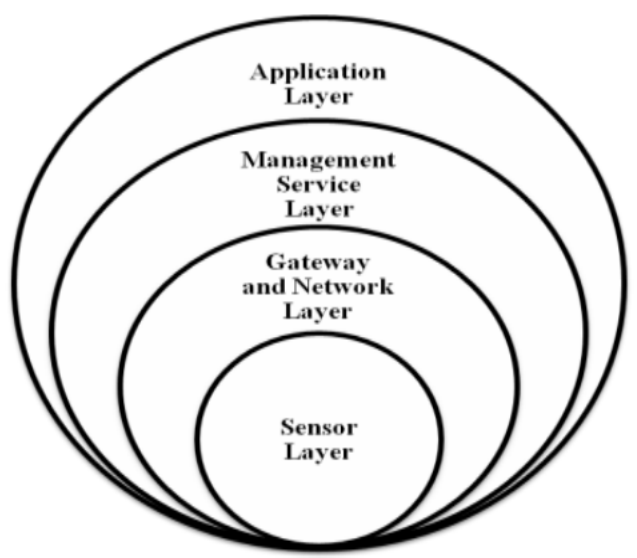

Figure 1: IoT Architecture

\section{RESEARCH METHOD}

In this section, the methodology for the adaptation of DV and IoT divided into four phases: system use case, system flowchart, the IoT implementation and data visualization implementation phases.

\subsection{System Use Case}

In order to portray the interaction of the event between the user and the application, a use case diagram illustrated using 
UML model. Figure 2 demonstrates the overall use case diagram on the interaction between the users of the system.

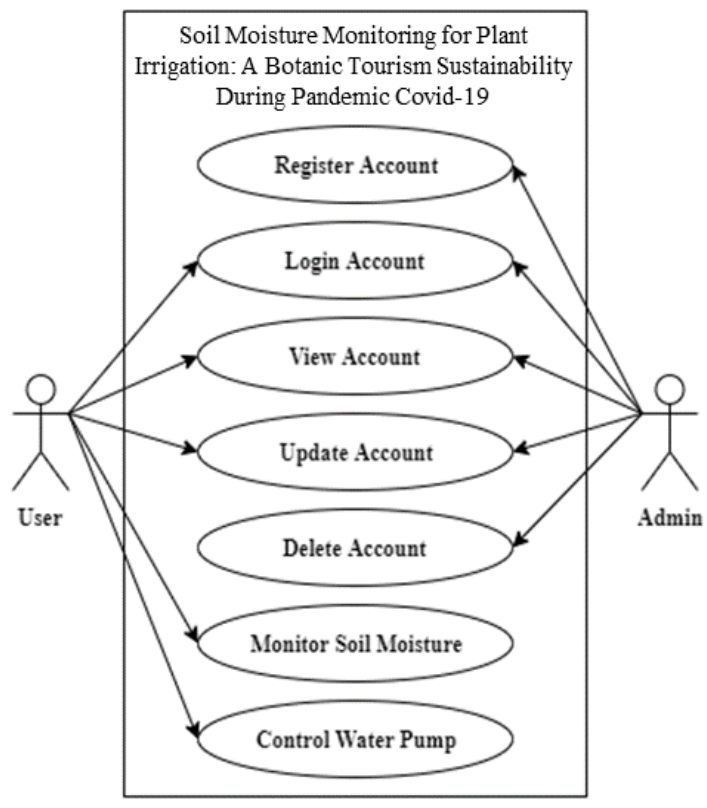

Figure 2: Overall Use Case Diagram

\subsection{System Flowchart}

The flow of the system for users shown in Figure 3.

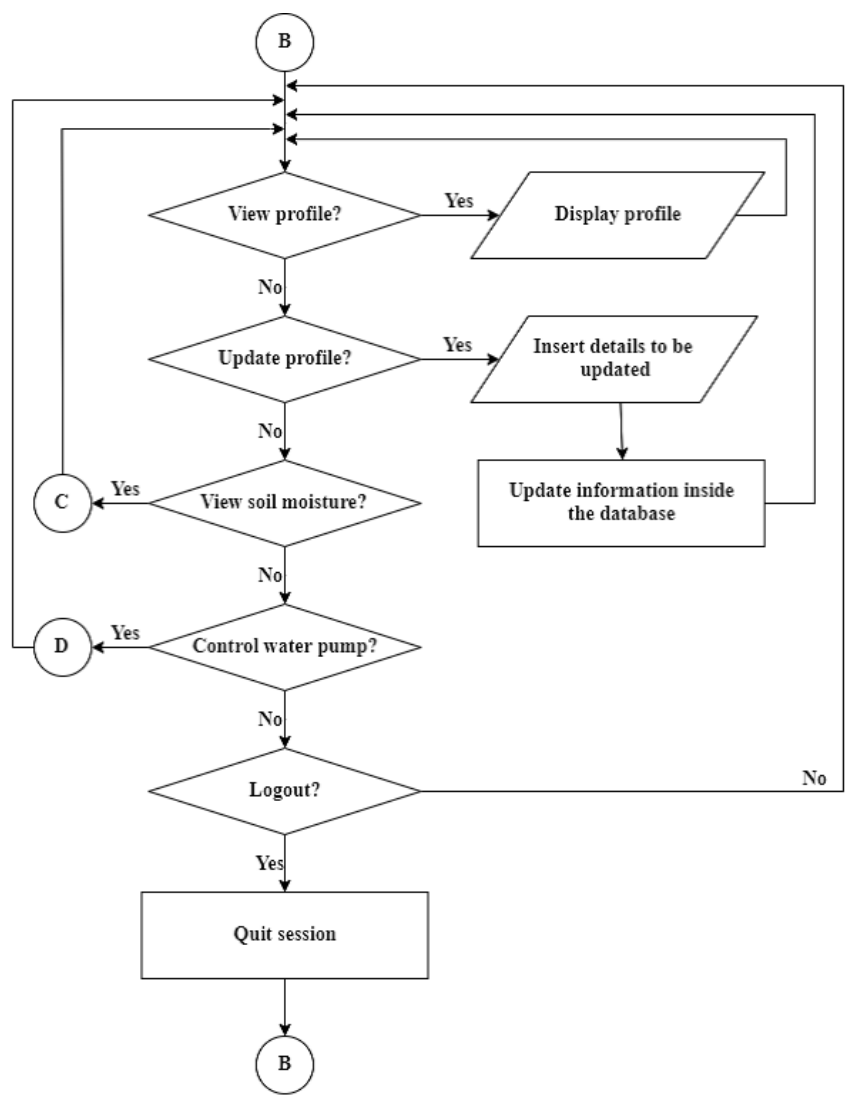

Figure 3: System Flowchart Diagram for User
Flowchart used to represent the flow or sequence of the application that can guide the developer to build the system from the start of the development process to the end. It used to illustrate the system step by step process so the system flow can easily be seen before the system development process starts. The flowchart is the first checklist for designing the system to keep a good structure for all functions of the system. Five options are given to the user on their homepage, which is view profile, update profile, view soil moisture, control water pump, and also logout. View soil moisture allows users to view the soil moisture data in the form of a line graph. Meanwhile, control water pump lets the users to either turn the water pump on or off.

\subsection{Internet of Things Implementation}

For this study, the chosen open-source computing platform is Arduino. For the microcontroller and communication module, NodeMCU Lolin ESP8266 connected to NodeMCU Base Board version 1.0 was used. Meanwhile, 4 Channel Isolated 5V Relay Module used for the power supply switch control. For the sensor and motor, Hygrometer Soil Sensor and R385 DC12V Diaphragm Water Pump were selected. Figure 4 illustrates a diagram to show the concept of the system on how the IoT worked. It shows the communication between the main mobile application and the components of IoT. First, a soil moisture sensor that was connected to the Arduino microcontroller sent the moisture reading to cloud storage. From the cloud storage, DV for the soil moisture reading constructed. With the constructed chart, the decision-making process took place to help users determine the amount of water they want to use for irrigation. Lastly, the water pump runs according to the amount requested from the main application.

In implementing the IoT, one of the most important things other than code is the device connection. Connecting devices using either jumper wires or AWG wires appropriately done to ensure the devices are correctly connected. Figure 5 illustrates the overall device connection from the NodeMCU main board to the hygrometer sensor, relay module, DC water pump, $12 \mathrm{~V}$ DC power adapter, and also the flow of water in and out the DC water pump. In order to keep the NodeMCU main board always turned on, $9 \mathrm{~V}$ alkaline battery used to supply the power to the mainboard for the hygrometer sensor and the relay module. 
K. A. F. A. Samah et al., International Journal of Emerging Trends in Engineering Research, 8(1.1), 2020, 82 - 89

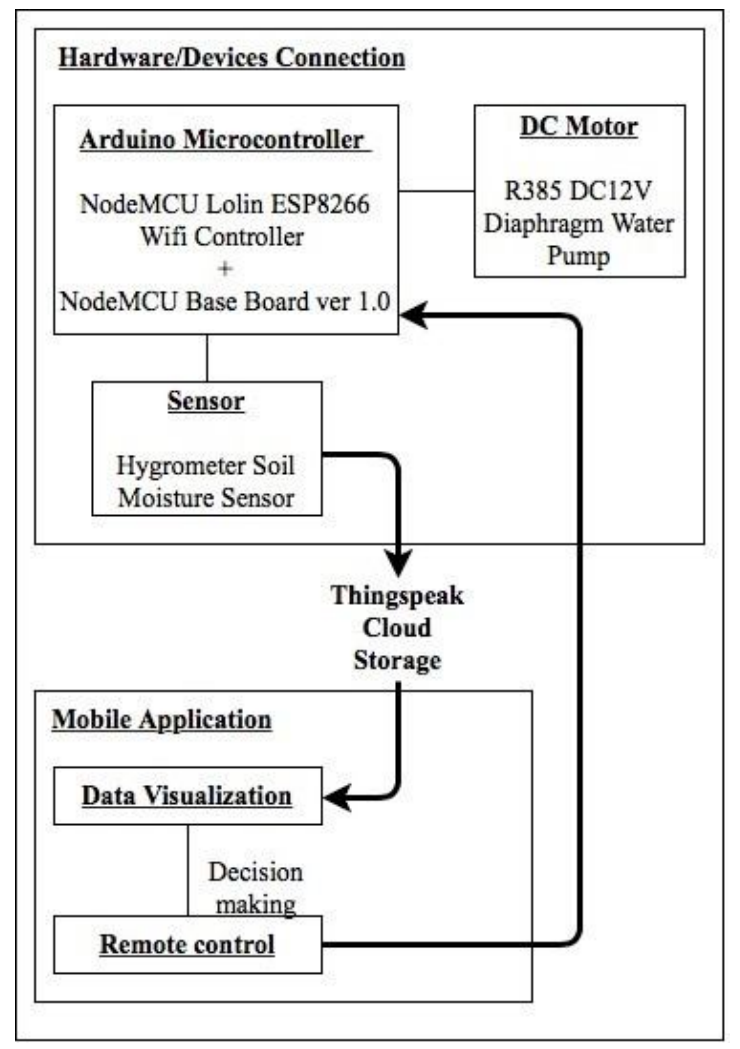

Figure 4 : System Flowchart Diagram for User

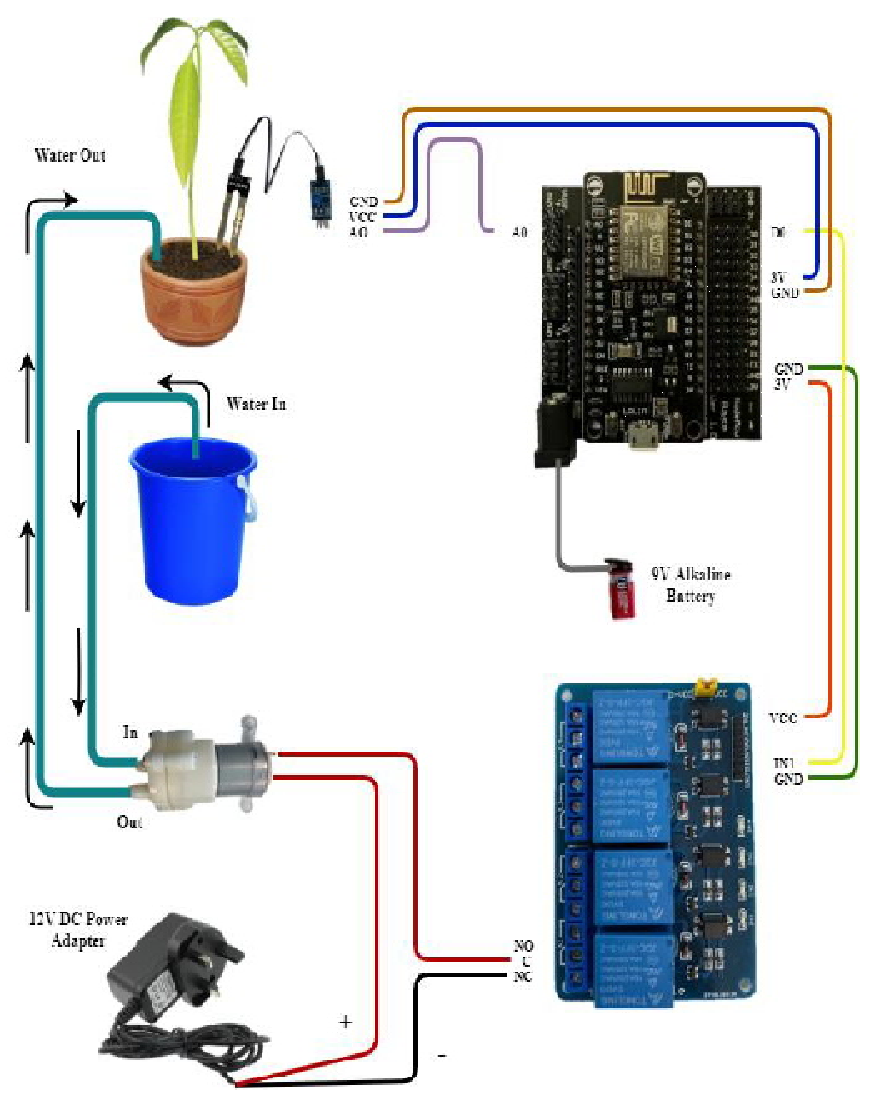

Figure 5: Overall Device Connection Diagram

\subsection{Data Visualization Implementation}

A time-series chart is the most suitable chart to be implemented. It is regarding the data that is collected is temporal data, which contains time of the data collected and moisture level reading. By providing a time series visualization, users can monitor the soil moisture from time to time and see the pattern of the water loss within the soil. Besides, normal users such as researchers can monitor the irrigation pattern and able to ensure that the plants irrigated according to the schedule.

Figure 6 shows the flow involved in data visualization. The hygrometer sensor reads moisture reading for every 15 seconds, and recorded into Thingspeak cloud storage. From the cloud, by using MATLAB visualization, a time series chart is generated. Users can alter the chart using a few options. The flow of this chart generation shown in Figure 6 .

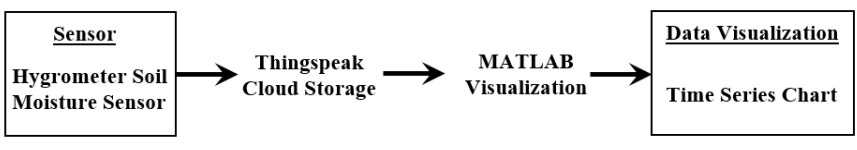

Figure 6: Data Visualization Flow

Knowing appropriate soil moisture content is essential because of irrigation decisions based on an accounting method on the water content in the soil [20]. Once the soil holds an appropriate amount of water, under-watering and over-watering are avoided. Moreover, maintaining an optimum water balance in the soil profile can trigger optimum growth and health for crop and production. Within soil, there is $45 \%$ mineral solid or the soil itself, $5 \%$ organic matter, and the remaining $50 \%$ is the combination of water and air. $50 \%$ of soil solids come from $45 \%$ of minerals and $5 \%$ organic. Meanwhile, around another $50 \%$ of pore space is from $20 \%-30 \%$ of water and $20-30 \%$ of air.

According to [21], optimum crop growth and health occur when the soil moisture content is in between $50 \%$ to $80 \%$ from time to time. However, the value of $80 \%$ moisture content may be too high for some types of plant that it may cause the roots to be drowned and dead. Table 2 shows the range for appropriate soil moisture content for this research.

Table 2: Functionality Test Result

\begin{tabular}{|c|c|}
\hline Soil Moisture Content Range & Remark \\
\hline $0-29$ & Under-watering \\
\hline $30-49$ & Need attention \\
\hline $50-70$ & Optimum \\
\hline $71-80$ & Need attention \\
\hline $81-100$ & Over-watering \\
\hline
\end{tabular}




\section{RESULT AND ANALYSIS}

This section discusses the results and findings gained from the proposed study for soil moisture monitoring for plant irrigation system using DV and IoT. The functionality and usability of the system tested to verify if the system had met the aim objectives. The target users for the testing phase would be researchers that are involved with irrigation activity. The feedback and result for this testing process were analyzed and recorded to identify the core problem to design solutions to fix the functionality and usability problem that happened during the testing process.

\subsection{Functionality Testing}

Functionality testing used to validate the result obtained from each function of the system. It checked on every function and examined whether it could produce the expected output or not. Each of the use cases tested in detail to see if the use case could work as expected. All tests showed a positive result of the functionality test based on the use case, as in Table 3 . Figure 7 shows the interface for the user to monitor soil moisture. Meanwhile, Figure 8 shows the interface for the user control water pump for irrigation activity.

Table 3: Visualization Techniques

\begin{tabular}{|l|l|c|}
\hline Use Case & \multicolumn{1}{|c|}{ Description } & Remark \\
\hline $\begin{array}{l}\text { Register } \\
\text { Account }\end{array}$ & $\begin{array}{l}\text { This use case allows the } \\
\text { admin of the system to add } \\
\text { a new user into the system }\end{array}$ & Passed \\
\hline $\begin{array}{l}\text { Login } \\
\text { Account }\end{array}$ & $\begin{array}{l}\text { This use case allows both } \\
\text { normal user and admin to } \\
\text { login into the homepage to } \\
\text { access the functions inside } \\
\text { the system }\end{array}$ & Passed \\
\hline $\begin{array}{l}\text { View } \\
\text { Account }\end{array}$ & $\begin{array}{l}\text { This use case permits both } \\
\text { user and admin to view } \\
\text { their account information }\end{array}$ & Passed \\
\hline $\begin{array}{l}\text { Update } \\
\text { Account }\end{array}$ & $\begin{array}{l}\text { This use case lets the user } \\
\text { and admin update their } \\
\text { account information }\end{array}$ & Passed \\
\hline $\begin{array}{l}\text { Delete } \\
\text { Account }\end{array}$ & $\begin{array}{l}\text { This use case allows admin } \\
\text { to delete any existing user } \\
\text { account within the system }\end{array}$ & Passed \\
\hline $\begin{array}{l}\text { Monitor } \\
\text { Soil } \\
\text { Moisture }\end{array}$ & $\begin{array}{l}\text { This use case lets only } \\
\text { normal user monitor soil } \\
\text { moisture that presented in } \\
\text { the form of the line chart }\end{array}$ & Passed \\
\hline $\begin{array}{l}\text { Control } \\
\text { Water } \\
\text { Pump }\end{array}$ & $\begin{array}{l}\text { This use case allows only } \\
\text { normal user to control the } \\
\text { water pump to water their } \\
\text { plants depending on the } \\
\text { amount the normal user } \\
\text { wants }\end{array}$ & Passed \\
\hline
\end{tabular}

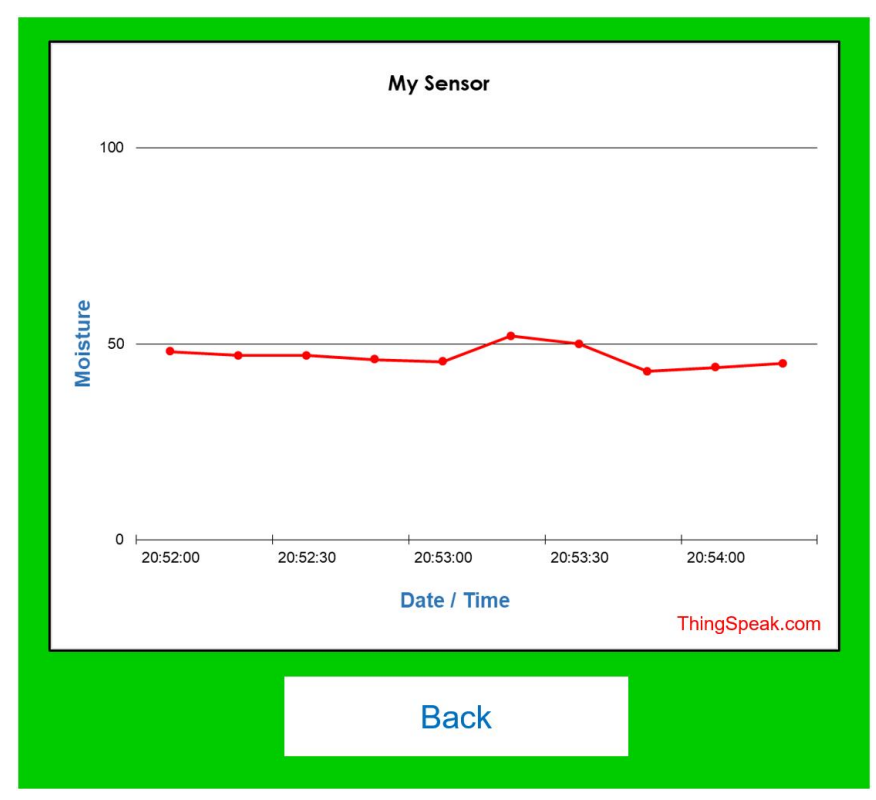

Figure 7: Soil Moisture in Line Graph

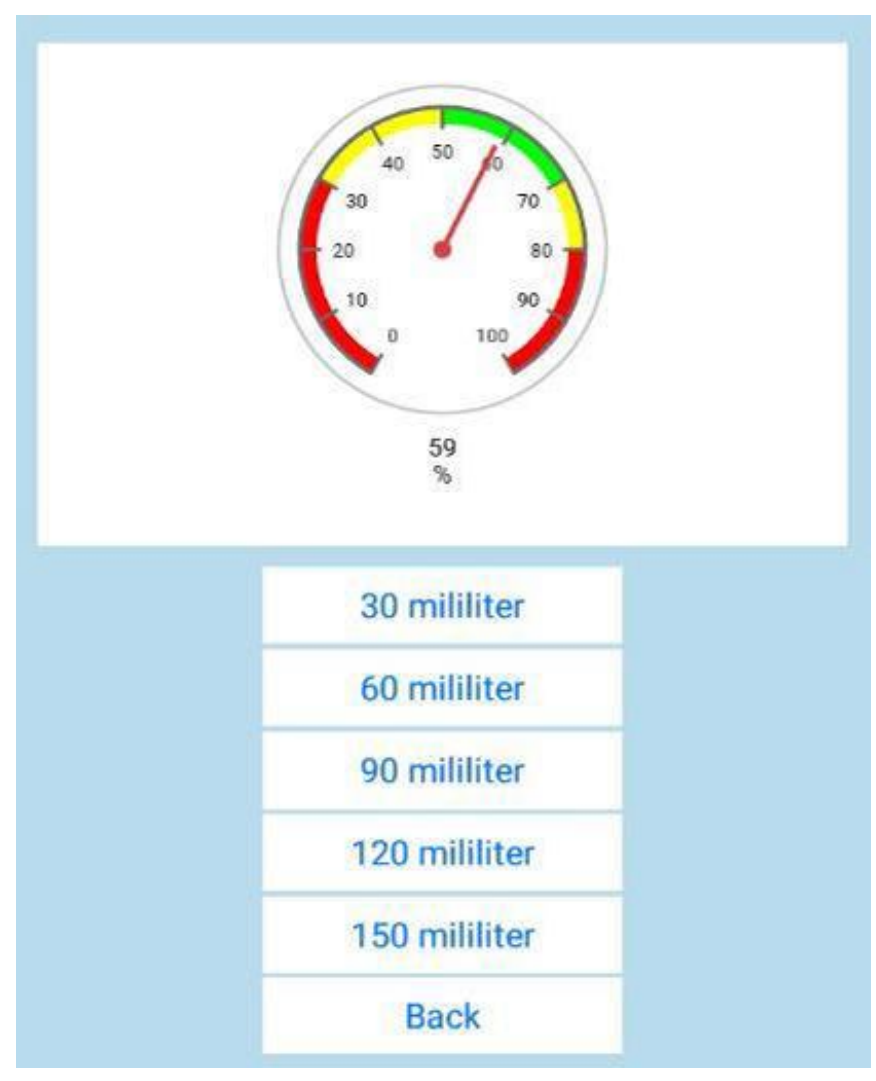

Figure 8: Soil Moisture Meter and Water Pump Control Options

\subsection{Usability Testing}

The respondents of the System Usability Scale (SUS) asked to record their survey responses immediately after they had tried using the fully developed system. All items must filled in, and the middle of the scale should be marked when the respondent felt that they could not respond to the specific items. 
Therefore, the survey could be carried out without any bias. For the current study, the respondents selected were 30 diploma students from the Faculty of Plantation and Agrotechnology (FPA) UiTM Cawangan Melaka Kampus Jasin. The respondents were asked to use the fully developed system and directly answered the questionnaire given. Once completed, all the responses recorded into the computer for analysis and result calculation. Figure 9 summarizes the SUS questionnaire score result on all 30 respondents for each of the questions given in the form of multiple bar charts.

\section{System Usability Scale (SUS) Result}

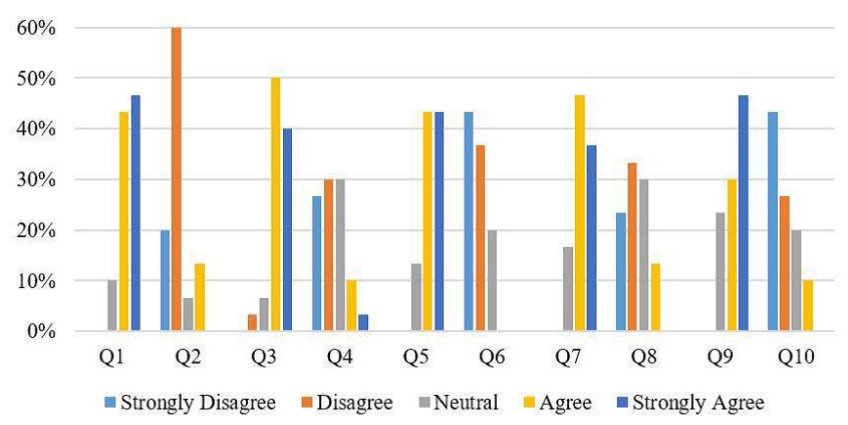

Figure 9: SUS Result by Question

SUS result scoring is calculated based on contributions on each item that is ranged from 0 to 4 . For odd number items, the score is the scale position subtract 1 , while for the even number items, the score is 5 subtract the scale position-list of scoring for each scale position for each item listed in Table 4.

Table 4: SUS Scoring

$\begin{array}{|l|c|c|}\hline \multicolumn{1}{|c|}{\text { Item }} & \text { Scale } & \text { Score } \\ \hline \text { Odd number item (Q1, } & 1 & 0 \\$\cline { 2 - 3 } \text {$Q3, Q5, Q7, Q9) } & 2 & 1 \\$\cline { 2 - 3 } & 3 & 2 \\ \cline { 2 - 3 } & 4 & 3 \\ \cline { 2 - 3 } & 5 & 4 \\ \hline \text {$\left.Even number item } \\ \text { (Q2, Q4, Q6, Q8, Q10) }\end{array}\right)$

The score from 30 respondents summed to get the score over 40. Then, multiplied by 2.5 to obtain the overall value of the system usability. The result is in the range of 0 to 100. Figure 10 shows a histogram of SUS scores. The range started at 55\% and followed by a new range for every $5 \%$. The frequency of each range shown in the vertical axis. Based on the histogram, the highest frequency is on the range of $70 \%$ to $75 \%$ score which 7 respondents fall under that range. 3 respondents scored within the lowest range, which is 55\% to
$60 \%$. Also, 4 respondents scored in between the highest range from $95 \%$ to $100 \%$.

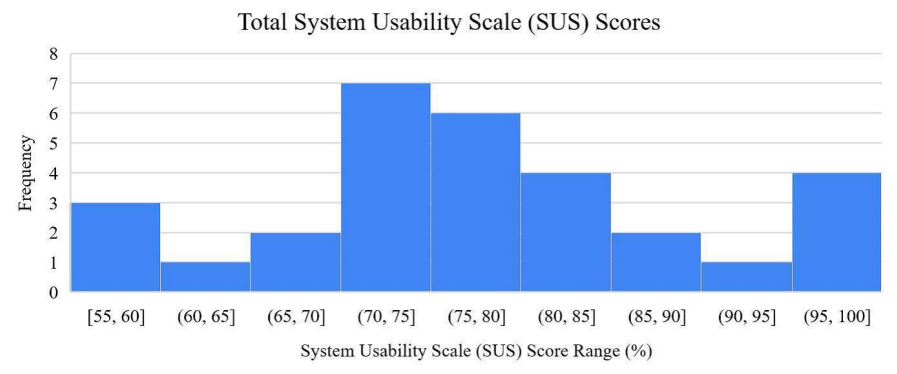

Figure 10: Histogram on System Usability Scale Score

As a result, the total score obtained from 30 respondents is 2322.5 and divided by the total number of respondents to get the average score. If the average score of SUS is $68 \%$, it means that the system has a good system usability whenever the score reaches or exceeds $68 \%$. Since the average SUS score obtained for the developed system is $77.4 \%$; thus, proven that the system has good usability.

\section{CONCLUSION}

In this research, the main aim was to develop an innovative system through a mobile application that provides a DV to monitor the soil moisture of the plant irrigation with the help of IoT. Due to the Covid-19 pandemic, this system was able to help in sustaining the botanic tourism and maintain the growth of the plant. In addition, the plant workers will not be exposed directly to any possibilities of infection, able to perform the new irrigation method remotely, and the researcher was able to monitor their soil moisture to decide the water amount the soil may need. At the same time, this preliminary study gives a contribution to the study in remote plant irrigation after being tested in both tests, functionality, and usability. This system can be enhanced for a better product and use by improving the hardware components such as a smarter and larger scale sensor.

\section{ACKNOWLEDGMENTS}

The research was sponsored by Universiti Teknologi MARA Cawangan Melaka under the TEJA Grant 2020 (GDT2020-14).

\section{REFERENCES}

1. A. K. A. Ahmed, X. Shi, L. Hua, L. Manzueta, W. Qing, T. Marhaba, and W. Zhang. Influences of air, oxygen, nitrogen, and carbon dioxide nanobubbles on seed germination and plant growth, Journal of Agricultural and Food Chemistry, vol. 66, no. 20, pp. 5117-5124, 2018.

2. E. Runkle and B. Bugbee. Problems with foot-candles, lux and lumen, Michigan State University, 78, 2013. 
K. A. F. A. Samah et al., International Journal of Emerging Trends in Engineering Research, 8(1.1), 2020, 82 - 89

3. M. Moore. Impact of coronavirus (covid-19) on tourist arrivals in the asia pacific region in 2020 , by country or region, Retrieved May 9, 2020, from https://www.statista.com/statistics/1103147/apac-covid -19-impact-on-tourist-arrivals-by-country/

4. M. Oduber, J. Ridderstaat, and P. Martens. The connection of vegetation with tourism development and economic growth: a case study for aruba. Journal of Environmental Science \& Engineering, vol. 4, pp. 420-431, 2015.

5. G. Viatte. Adoption of technologies for sustainable farming systems: an oecd perspective, in Wageningen Workshop Proceedings, 2001, pp. 14-23.

6. J. J. Otten, K. Cheng, and A. Drewnowski. Infographics and public policy: using data visualization to convey complex information, Health Affairs, vol. 34, no. 11, pp. 1901-1907, 2015.

7. H. Kirnak, I. S. Varol, H. A. Irik, and H. Ozaktan. Effects of irrigation applied at different growth stages on chickpea yield, Agronomy Research, vol. 15, no. 5, pp. 1928-1933, 2017.

8. T. D. Landis, and K. M. Wilkinson. Water quality and irrigation. Nursery manual for native plants: a guide for tribal nurseries, Nursery Management, vol. 1, pp. 177-199, 2009.

9. D. L. Scarnecchia and F. Magdoff. (1994). Building soils for better crops. Organic matter management, Journal of Range Management, vol. 47, no. 4, pp. 315, 1994.

10. M. S. M. Amin and A. I. M. Ekhmaj. Dipac-drip irrigation water distribution pattern calculator, in 7th Int. Micro Irrigation Congress, PWTC, Kuala Lumpur, Malaysia, 2016, pp. 503-513.

11. K. Punjab. Research paper on drip irrigation management using wireless sensors, International Journal of Computer Networks and Wireless Communications (IJCNWC), vol. 2, no. 4, pp. 461-464, 2012.

12. A. Carter and J. Howell. (2006). An overview of drip irrigation, Plant and Soil, pp. 1-12, 2016.

13. T. Scherer. Selecting a sprinkler, North Dakota State University Extension Service, 2018.

14. S. Irmak, J. O. Payero, D. L. Martin, A. Irmak and T. A. Howell. Sensitivity analyses and sensitivity coefficients of standardized daily asce-penman-monteith equation, Journal of Irrigation and Drainage Engineering, vol. 132, no. 6, pp. 564-578, 2006.

15. A. J. Mila, S. Chakraborty, N. Islam and P. K. Sarkar. Evaporation loss during sprinkler irrigation, Bangladesh Journal of Scientific Research, vol. 23, no. 2, pp. 1-9, 2011.

16. L. R. Sinobas, M. G. Rodriguez. A review of subsurface drip irrigation and its management, Water Quality, Soil and Managing Irrigation of Crops, pp. 171-194, 2012.
17. A. Vadagave, M. Safa, S. S. Sokhi, B. Mathur and B. Anirudh. Enhancing smart precision agriculture in iot using agroecological analysis, International Journal of Advanced Science and Technology, vol. 29, no. 6, pp. 2750-2760, 2020.

18. S. G. Hegde and Soumyalatha. Study of iot: understanding iot architecture, applications, issues and challenges, in 1st International Conference on Innovations in Computing \& Networking, 2017, pp. 477-482.

19. D. Evans. The internet of things: how the next evolution of the internet is changing everything, CISCO White Paper, vol. 1, pp. 1-11, 2011.

20. U. Saha, A. Fayiga and L. Sonon. Selenium in the soil-plant environment: a review, International Journal of Applied Agricultural Sciences, vol. 3, no. 1, pp. 1-18, 2017.

21. F. Shaxson and R. Barber. Optimizing soil moisture for plant production. The significance of soil porosity, FAO Soils Bulletin 79, pp. 72-76, 2003. 